\title{
Investigation of glycerol doping on ignition delay times and laminar burning velocities of gasoline and diesel fuel
}

Glycerol is a major by-product of biodiesel production. Per one tone of produced biodiesel, one hundred kilograms of glycerol is produced. Production of glycerol is increasing due to increase of demand for biodiesel. One of methods of glycerol utilization is combustion. Recent experimental studies with use of a diesel engine and a constant volume combustion chamber show that utilization of glycerol as a fuel results in lower $\mathrm{NO}_{x}$ emissions in exhaust gases. It combusts slower than light fuel oil, what is explained by higher viscosity and density of glycerol. Glycerol has low cetane number, so to make combustion in a diesel engine possible at least one of the following conditions need to be fulfilled: a pilot injection, high temperature or high compression ratio. The aim of the paper is to compare glycerol to diesel and to assess influence of glycerol doping on gasoline and diesel fuel in dependence of pressure, temperature and equivalence ratio. The subject of this study is analysis of basic properties of flammable mixtures, such as ignition delay times and laminar burning velocities of primary reference fuels (diesel: $n$-heptane and gasoline: iso-octane). Calculations are performed with use of Cantera tool in Matlab and Python environments. Analyses of influence of glycerol on ignition delay times of $n$-heptane/air and iso-octane/air mixtures covered wide range of conditions: temperatures from 600 to $1600 \mathrm{~K}$, pressure 10-200 bar, equivalence ratio 0.3 to 14, molar fraction of glycerol in fuel 0-1 in air. Simulations of LBV in air cover temperatures: 300 K and 500 K, pressures: 10, 40, 100, 200 bar and equivalence ratio from 0.3 to 1.9. Physicochemical properties of gasoline, diesel and glycerol are compared.

Key words: glycerol, ignition delay times, laminar burning velocities, Cantera, gasoline, diesel

\section{Introduction}

Glycerol (chemical formula: $\mathrm{C}_{3} \mathrm{H}_{8} \mathrm{O}_{3}$ ) is a major byproduct of biodiesel production. Biodiesel is produced by transestrification of triglycerides (fats, oils, etc.) into fatty acid methyl esters [1]. The triglyceride reacts with an alcohol and a catalyst (i.e. sodium hydroxide) to produce FAME and glycerol (Fig. 1). Per one tone of produced biodiesel, one hundred kilograms of glycerol is produced. Depending on the process, the glycerol waste may contain variable amounts of alcohol, water, catalyst and other organic materials - soaps, fats, oils. Production of glycerol is increasing due to increase of demand for biodiesel. It is one of the most versatile chemical species. It is completely soluble in water and alcohols, but it is insoluble in hydrocarbons. It is widely used in the food industry, in pharmaceutical formulations and in cosmetics [2]. However, in order to utilize waste glycerol in this way it need to be purified, what requires more time and equipment. Instead, raw glycerol can be utilized as a fuel in an engine, by the way increasing a biofuel pool.

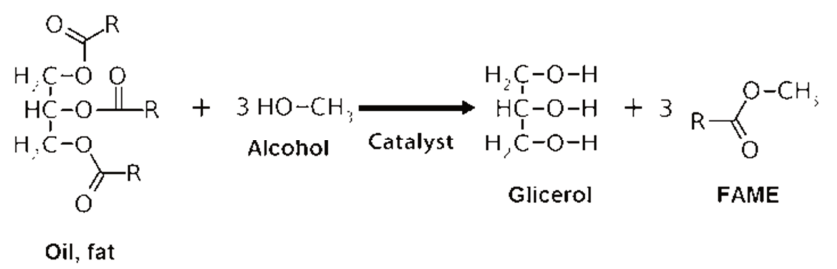

Fig. 1. Process of transestrification [1]

However, glycerol is much different from diesel fuel and kerosene. Main issues with using it in compression ignition engines is low cetane number and high viscosity [3]. A few researches on utilizing glycerol as a fuel were conducted. Rychlik et al. [4] presented the method of gly- cerine combustion in a diesel engine without necessity of using pilot fuel or additives improving the cetane number of a fuel in the form of glycerol. They used MTU V652 engine (12 MW power) and $98.5 \%$ technical glycerol. Reliable work of the diesel engine on glycerol was possible thanks to preheating of the fuel up to $98-105^{\circ} \mathrm{C}$ (kinematic viscosity dropped to ca $8 \mathrm{~mm}^{2} / 2$ ) and preheating of intake air in a heat exchanger by exhaust gas from $140^{\circ} \mathrm{C}$ to $190^{\circ} \mathrm{C}-$ $200^{\circ} \mathrm{C}$ (boost pressure dropped from 1.5 atm to $1.3 \mathrm{~atm}$ ). Fuel consumption increased 2.25 times. McNeil [5] used glycerol in both naturally aspirated and turbo-charged engines with intake manifold heating. Natural aspiration required intake air heating to $144^{\circ} \mathrm{C}$ to sustain combustion compared to turbocharged operation at $100^{\circ} \mathrm{C}$ because glycerol has poor ignitability (cetane number $=0-5[3,5]$ ). Lower energy density requires nearly double fueling rates to achieve equivalent power output compared to diesel fuel. Stelmasiak and Pietras [6] investigated effects of methanol and a blend of methanol and glycerin on parameters of automotive spark ignition engine of the Fiat 1100 MPI type (40 kW power). Addition of glycerin resulted in higher efficiency of the engine compared to pure methanol or gasoline E95. They tried to mix glycerin with diesel oil or gasoline. Despite of intensive mixing either a mixture with diesel oil or gasoline completely segregated after 15-20 minutes. Grab-Rogaliński and Szwaja [7] performed tests in a combustion research unit (a constant volume combustion chamber with injection system) with light fuel oil or glycerol. They concluded that glycerol combusts slower than LFO, because of poorer atomization due to higher viscosity and density of glycerol. Combustion of pure glycerol was not possible, a pilot injection of diesel fuel was necessary. Eaton et al. [8] showed glycerol/diesel emulsion can be produced using commercially available surfactants. Their research in a single-cylinder diesel engine with blends of 
diesel oil and 10 vol. $\%$ or 20 vol.\% of glycerol showed that combustion of the emulsion fuels at $900 \mathrm{rpm}$ in a naturally aspirated engine resulted in nominal combustion delay, likely because of a lower cetane rating compared to diesel oil. Benefits of glycerol emulsification include increased thermal efficiency at high engine loads and reductions in $\mathrm{NO}_{\mathrm{x}}$ and PM emissions of 5-15 and $25-50 \%$, respectively.

The goal of this paper is to compare key thermo physical properties of glycerol to both gasoline and petroleum diesel oil in terms of combustion in engines.

\section{Fuel properties}

Ignition delay time and laminar burning velocity are fundamental properties characterizing a flammable mixture [9]. IDT and LBV are a direct reflection of fuel's chemical kinetics. The most important properties of a fuel for its application in an engine are kinematic viscosity, density, heating value, flash point, pour point, cloud point, cetane number etc. These properties directly influence engine's performance and emissions. The most common standard to define the limit of most of these properties for diesel is ASTM [10].

\subsection{Ignition delay time}

Glycerol has relatively low vapor pressure, i.e. $1 \mathrm{~mm}$ $\mathrm{Hg}$ in $125.5^{\circ} \mathrm{C}$ [2]. This makes investigation of IDT in a shock tube or a rapid compression machine difficult. Devices would need to be heated up to $200-300^{\circ} \mathrm{C}$ in order to reach a reasonable level of vapor pressure of glycerol to perform an experiment. For authors best knowledge there are no experimental information on IDT of glycerol in literature. Therefore a development of a detailed chemical kinetics mechanism for oxidation of glycerol was not trivial and only one scheme is found - POLIMI BIO 1412 [1115]. Barker-Heming et al. [14] performed validation of their chemical scheme based on reduced-gravity experiments on combustion of propanol/glycerol mixture droplets [16]. Gasoline and diesel oil are complex blends of hydrocarbons. As surrogate fuels for chemical kinetic investigation iso-octane and n-heptane respectively are used. The mechanisms to be used in this investigations ought to contain either n-heptane/glycerol/air or iso-octane/glycerol/air chemistry. One mechanism fulfills this condition - POLIMI TOT 1412 [17] (which contains POLIMI BIO 1412 scheme).

Fig. 2 and Fig. 3 present a comparison of exemplary shock tube experimental ignition delay times [18, 19] with those simulated using POLIMI TOT 1412. Two data sets of IDT from shock tube experiments were collected for stoichiometric n-heptane/air and iso-octane/air. The first set is for 15,20 and 38 bar for temperature from 727 to $1413 \mathrm{~K}$ [19] -24 points in total. The second set is for pressures from 6.9 to 47.4 bar and temperatures from 713 to $1242 \mathrm{~K}$ [18] - 50 points in total. Ignition delay time simulations were performed in a constant volume reactor with adaptive time step in Cantera 2.3.0 [20] in Matlab R2016b environment. Initial conditions for simulations were experimental temperature and pressure behind a reflected shock wave and composition of a currently investigated mixture. Definition of IDT in simulations was the same as used in the experiments $[18,19]$. It is worth to notice that for the sec- ond set of IDT experimental pressure varied from point to point, what influenced presentation of the comparison results on Fig. 3 (simulated points are not connected by a line). This brief validation of the mechanism shows that ignition delay time of iso-octane and n-heptane are well enough reproduced by POLIMI TOT 1412. The highest difference is visible for temperatures lower than $1000 \mathrm{~K}$ in the region of negative temperature coefficient. One can notice that the mechanism was not validated for blends of species investigated in this paper.

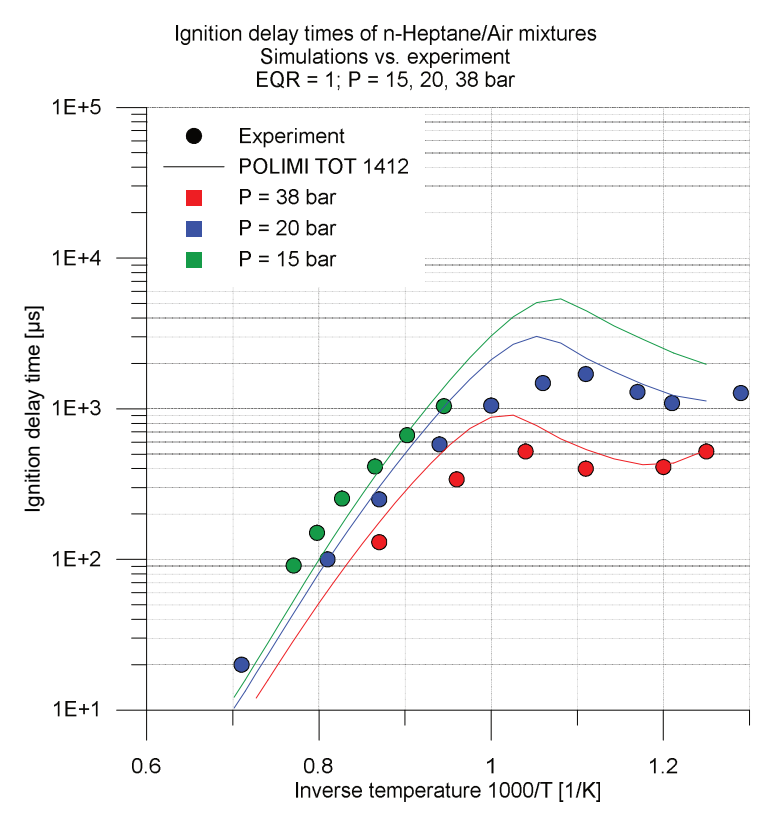

Fig. 2. Ignition delay times of stoichiometric n-heptane/air mixture for 15 , 20, 38 bar: solid line - simulated IDT using POLIMI TOT 1412 mechanism, circles - experimental IDT [19]

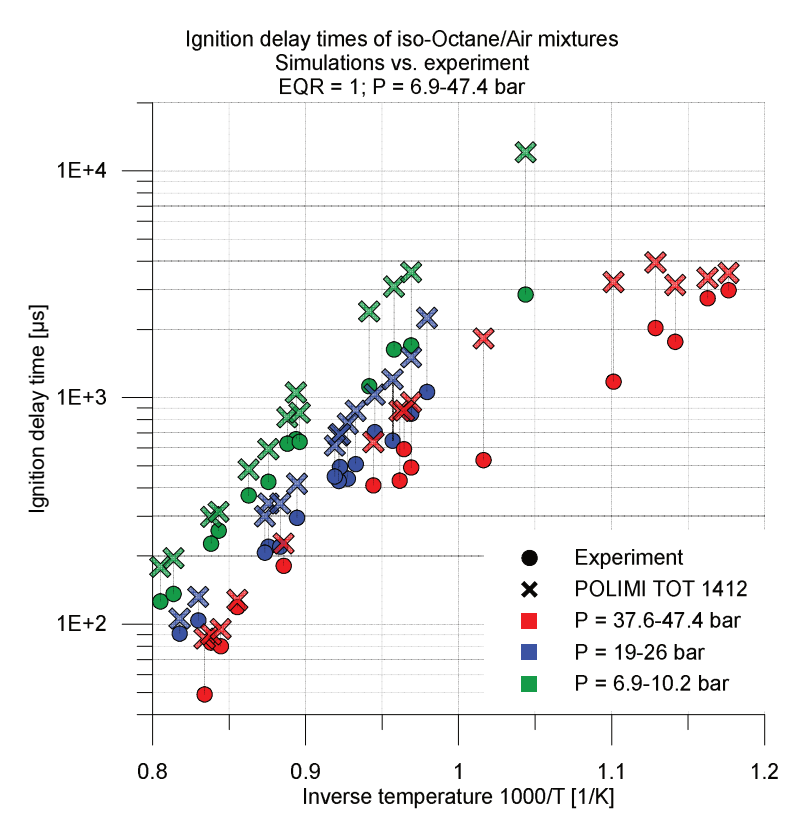

Fig. 3. Ignition delay times of stoichiometric iso-octane/air mixture for pressures 6.9-47.4 bar: solid line - simulated IDT using POLIMI TOT 1412 mechanism, circles - experimental IDT [18]

Analyses of influence of glycerol on n-heptane/air and iso-octane/air mixtures covered wide range of conditions: 
temperatures from 600 to $1600 \mathrm{~K}$, pressure $10-200 \mathrm{bar}$, equivalence ratio 0.3 to 14 , molar fraction of glycerol in fuel 0-1 (from pure n-heptane or iso-octane to pure glycerol) in air. Assumed IDT definition is a time interval from the onset of simulation up to maximal gradient of temperature rise.

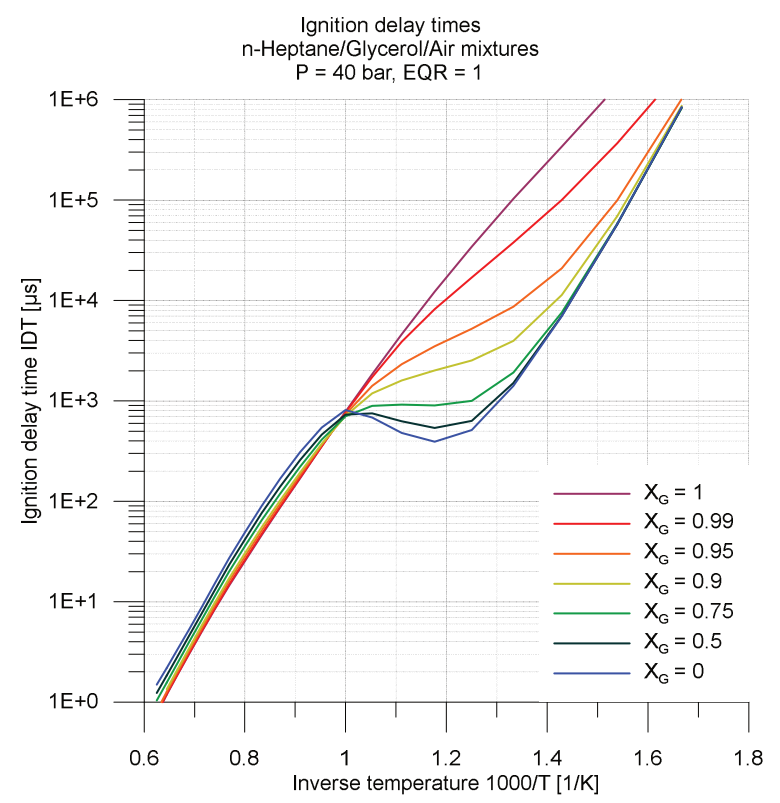

Fig. 4. Ignition delay time vs. inverse temperature of n-heptane - glycerol blends for 40 bar and equivalence ratio equal to 1 for different glycerol molar fraction in a fuel $\mathrm{X}_{\mathrm{g}}$

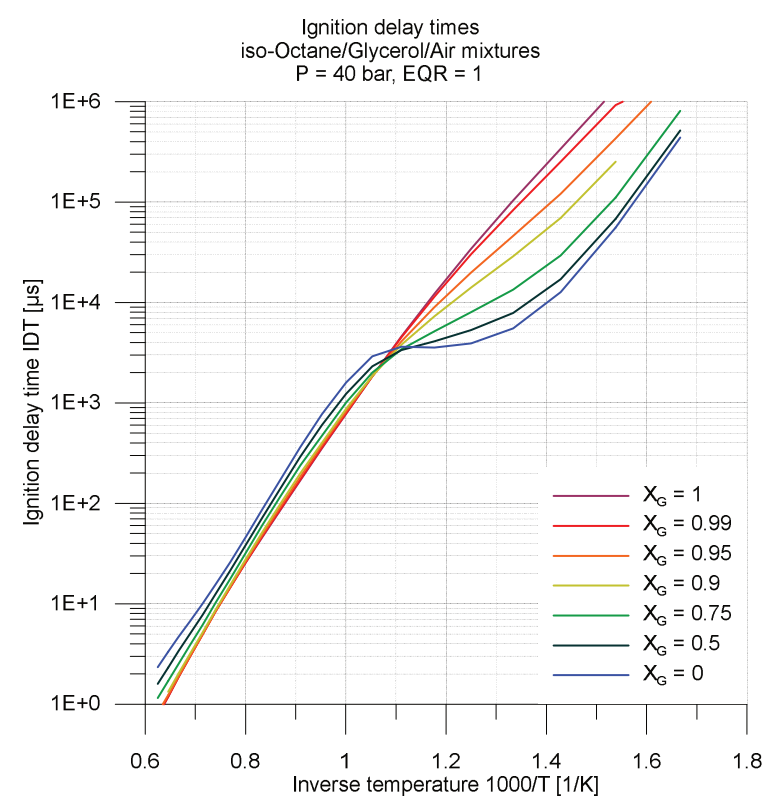

Fig. 5. Ignition delay time vs. inverse temperature of iso-octane - glycerol blends for 40 bar and equivalence ratio equal to 1 for different glycerol molar fraction in a fuel $\mathrm{X}_{\mathrm{g}}$

Fig. 4 and Fig. 5 present IDT of stoichiometric mixtures of n-heptane/glycerol/air and iso-octane/glycerol/air respectively for 40 bar. Glycerol does not have a negative temperature coefficient region as opposed to n-heptane and isooctane. For high temperatures $(\mathrm{T}>1000 \mathrm{~K}$ for $\mathrm{n}$-heptane and $\mathrm{T}>900 \mathrm{~K}$ for iso-octane) glycerol and blends with glycerol have shorter IDTs than n-heptane and iso-octane, but the difference is small. For lower temperatures $(\mathrm{T}<$ $1000 \mathrm{~K}$ for $\mathrm{n}$-heptane and $\mathrm{T}<900 \mathrm{~K}$ for iso-octane) lines intersect and then the difference is opposite. Glycerol and blends with glycerol have much longer IDT. The highest difference is present for NTC regions and may reach even 2 orders of magnitude for $\mathrm{n}$-heptane and 1 for iso-octane.

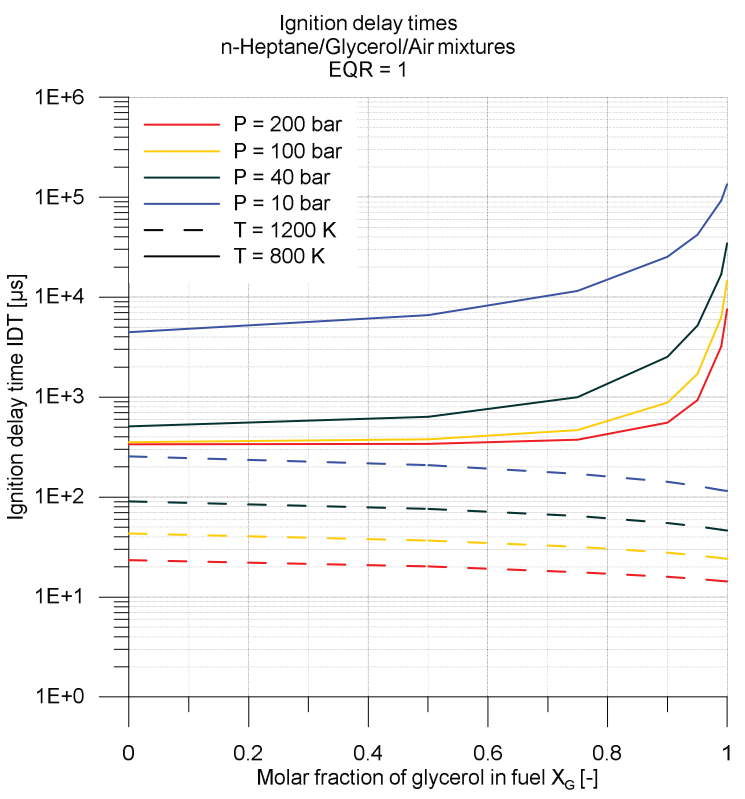

Fig. 6. Ignition delay time of stoichiometric n-heptane - glycerol mixtures vs. molar fraction of glycerol in fuel $\mathrm{X}_{\mathrm{g}}$ for 4 pressures $(10 \mathrm{bar}$ - blue line, $40 \mathrm{bar}$ - dark green line, $100 \mathrm{bar}$ - yellow line, $200 \mathrm{bar}$ - red line) and 2 temperatures ( $800 \mathrm{~K}$ - solid line, $1200 \mathrm{~K}$ - dashed line)

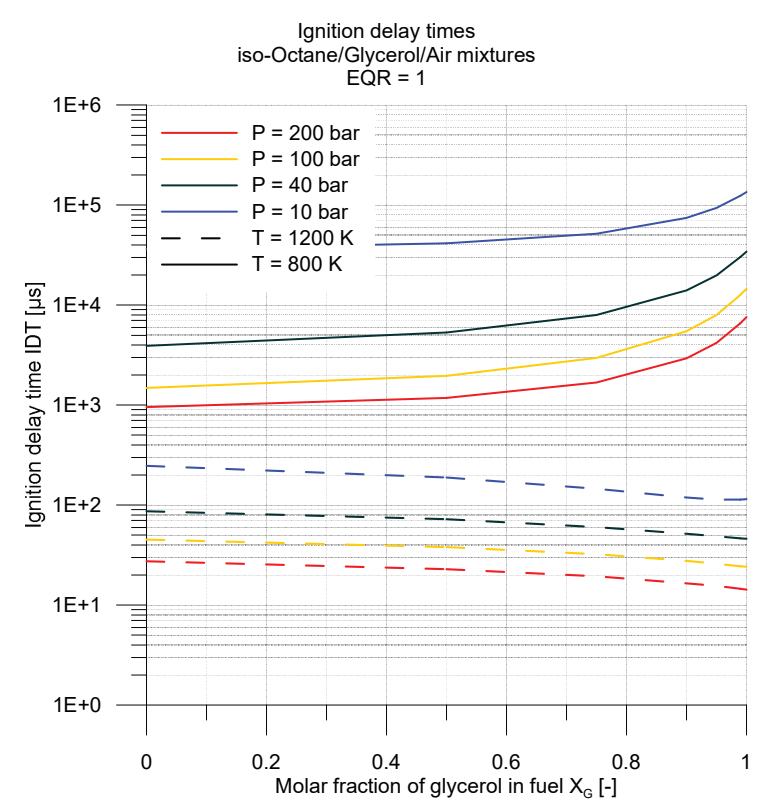

Fig. 7. Ignition delay time of stoichiometric iso-octane - glycerol mixtures vs. molar fraction of glycerol in fuel $\mathrm{X}_{\mathrm{g}}$ for 4 pressures $(10 \mathrm{bar}$ - blue line, $40 \mathrm{bar}$ - dark green line, $100 \mathrm{bar}$ - yellow line, $200 \mathrm{bar}$ - red line) and 2 temperatures ( $800 \mathrm{~K}$ - solid line, $1200 \mathrm{~K}$ - dashed line)

Next figures present IDT of stoichiometric mixtures of both n-heptane (Fig. 6) and iso-octane (Fig. 7) with glycerol vs. molar fraction of glycerol in a fuel $\mathrm{X}_{\mathrm{g}}$ for 4 example pressures $(10,40,100,200 \mathrm{bar})$ and 2 temperatures $(800 \mathrm{~K}$ 
and $1200 \mathrm{~K}$ ). IDTs are almost constant in a wide range of glycerol molar fraction. Shape of plots changes with pressure as NTC region moves with pressure. Glycerol is not a fuel additive. It is possible to preserve IDT of n-heptane or iso-octane for relatively high amounts of glycerol. Isooctane is more prone for glycerol's influence than nheptane. Behavior described in previous paragraph might be noticed here also. For n-heptane - glycerol and isooctane - glycerol blends there is a temperature where a way of IDT's change switches - for very high temperatures glycerol has lower IDTs than both n-heptane and isooctane, but still this difference is small.

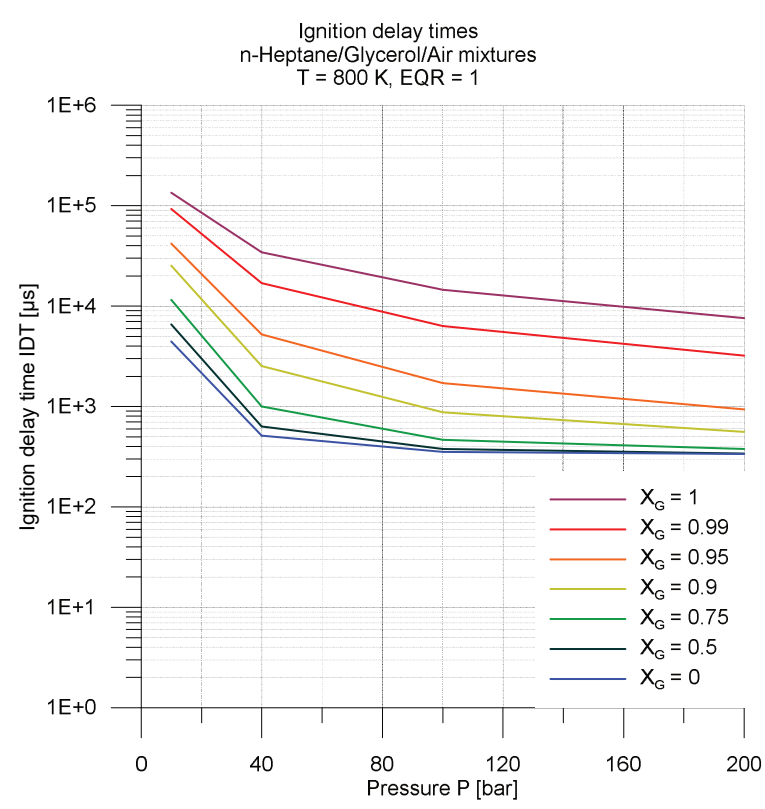

Fig. 8. Ignition delay time vs. pressure of stoichiometric n-heptane glycerol blends for $800 \mathrm{~K}$ for different glycerol molar fraction in a fuel $\mathrm{X}_{\mathrm{g}}$

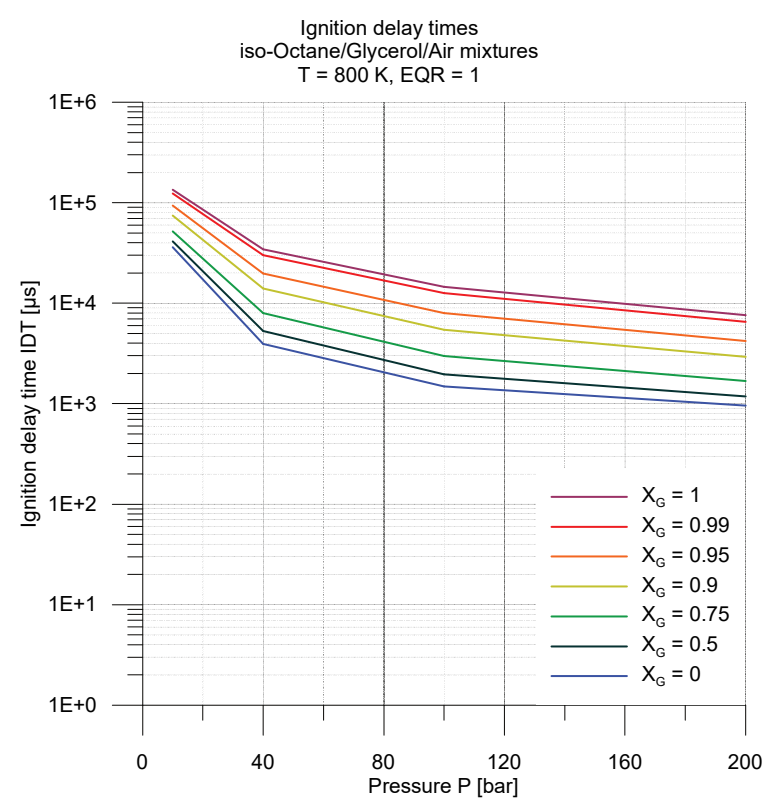

Fig. 9. Ignition delay time vs. pressure of stoichiometric iso-octane - glyc-erol blends for $800 \mathrm{~K}$ for different glycerol molar fraction in a fuel $\mathrm{X}_{\mathrm{g}}$

Fig. 8 and Fig. 9 show how ignition delay time changes with pressure for stoichiometric iso-octane/glycerol and n- heptane/glycerol blends for 7 glycerol molar fractions in a fuel for $800 \mathrm{~K}$. IDT gets smaller when pressure increases. The difference between $n$-heptane and glycerol is higher than between gasoline and glycerol. The biggest difference for Fig. 8 is for 40 bar and n-heptane's IDT is 2 orders of magnitude higher than glycerol's. For gasoline the difference an order of magnitude of difference. Again, one can notice that n-heptane's and iso-octane's low IDT are persisted in a wide range of glycerol molar fraction in a fuel. The difference for both between $\mathrm{X}_{\mathrm{g}}=0$ and $\mathrm{X}_{\mathrm{g}}=0.5$ is negligible.

\subsection{Laminar burning velocity}

Laminar burning velocities are calculated in Cantera 2.3.0. in Python 3.5.3 environment using free flame model and automatic refinement of a grid. Diffusive mass fluxes due to the Soret effect are not included. Due to the high number of species and reactions in POLIMI TOT 1412 (451 species and 17848 reactions) 3 smaller chemical schemes are used. POLIMI BIO 1412 (137 species and 4522 reactions) for calculations of glycerol. Jerzembeck [21] reaction mechanism (99 species and 601 reactions) for n-heptane to simulate diesel fuel chemistry. Liu et al. [22] skeletal chemical kinetic model of iso-octane for internal combustion engines (33 species and 116 reactions). None of the three mechanisms handles chemistry of either glycerol/iso-octane or glycerol/n-heptane blends, so calculations are performed only for pure species - pure glycerol, pure n-heptane and pure iso-octane. Simulations of LBV in air cover temperatures: $300 \mathrm{~K}$ and $500 \mathrm{~K}$, pressures: 10, 40, 100, 200 bar and equivalence ratio from 0.3 to 1.9 .

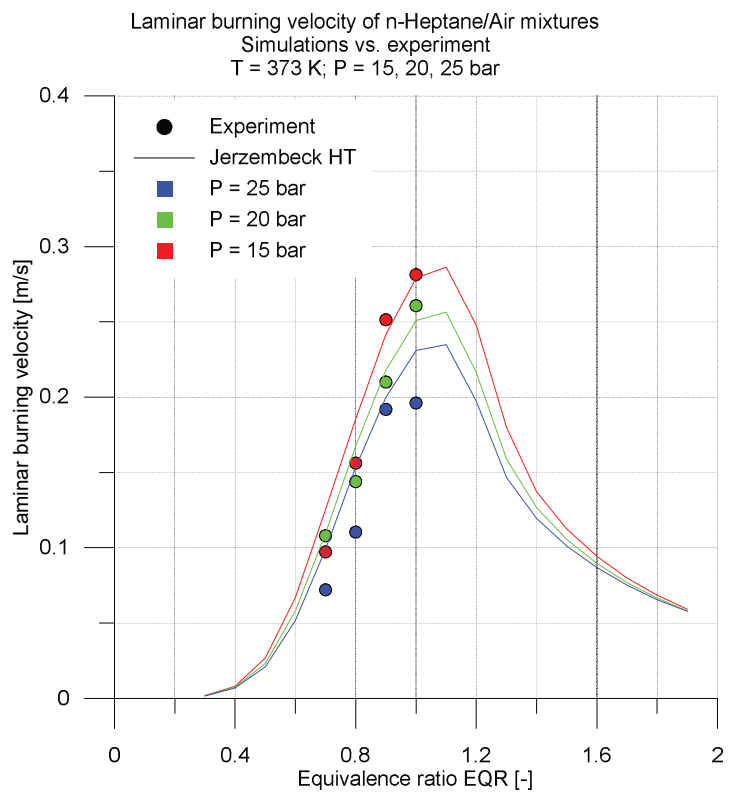

Fig. 10. Laminar burning velocities of $n$-heptane/air mixtures for pressures 15, 20, 25 bar: solid line - simulated LBV using Wisconsin ERC mechanism, circles- experimental LBV [21]

Fig. 10 and Fig. 11 present a brief comparison of experimental LBV with calculated ones for n-heptane/air and isooctane/air mixtures using mentioned above mechanisms. Experimental LBV of glycerol/air blends are not present in literature. The chosen data set for n-heptane from Jerzem- 
beck et al. [21] is for $373 \mathrm{~K}$, pressures: 15, 20, $25 \mathrm{bar}$ and $\mathrm{EQR}$ from 0.7 to 1.0 . Jerzembeck mechanism predicts very well LBVs. Iso-octane/air experimental data from Jerzembeck et al. [21] are for the same conditions as n-heptane/air for EQR from 0.7 to 1.2. Liu et al. [22] mechanism's predictions are very consistent with experimental results for lean mixtures, for rich mixtures the mechanism's LBVs are $\sim 20 \%$ smaller.

Fig. 12 and Fig. 13 compare LBV of n-heptane/air with glycerol/air mixtures for $500 \mathrm{~K}$ and $300 \mathrm{~K}$ respectively. Nheptane has higher LBVs. For near stoichiometric conditions the difference is $\sim 15 \%$. Change of temperature from $500 \mathrm{~K}$ to $300 \mathrm{~K}$ results in drop of LBV by $60 \%$ for both mixtures.

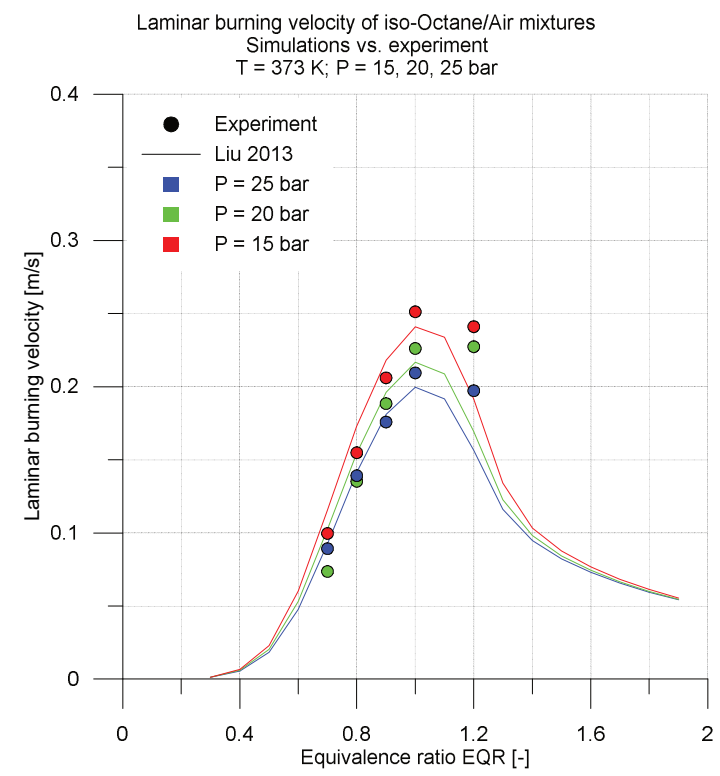

Fig. 11. Laminar burning velocities of iso-octane/air mixtures for pressures 15, 20, 25 bar: solid line - simulated LBV using Wisconsin ERC mechanism, circles - experimental LBV [21]

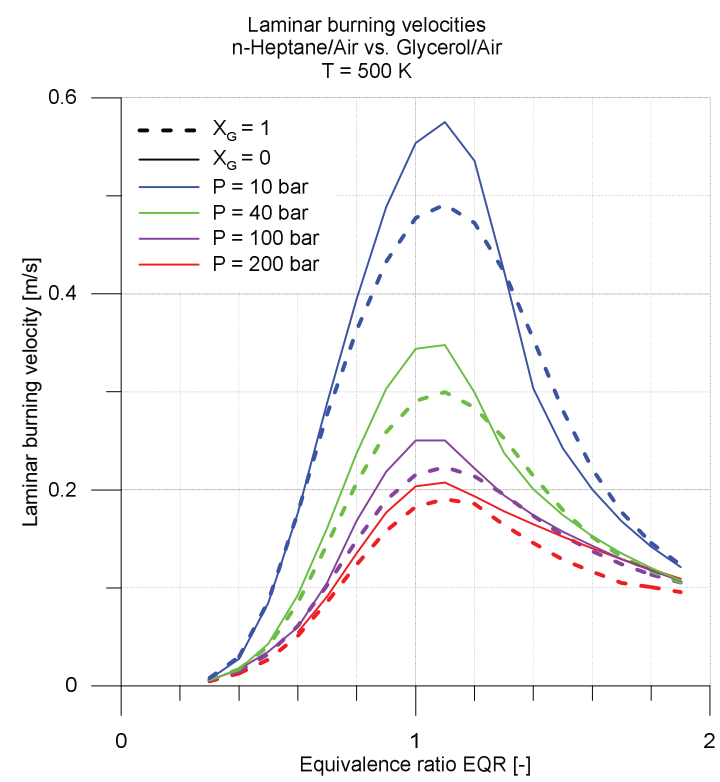

Fig. 12. Laminar burning velocity for $n$-heptane/air $\left(\mathrm{X}_{\mathrm{g}}=0\right.$, solid lines $)$ and glycerol/air $\left(X_{\mathrm{g}}=1\right.$, dashed lines) mixtures for $500 \mathrm{~K}$ and 4 pressures (10 bar - blue line, 40 bar - green line, 100 bar - violet line, 200 bar - red line)

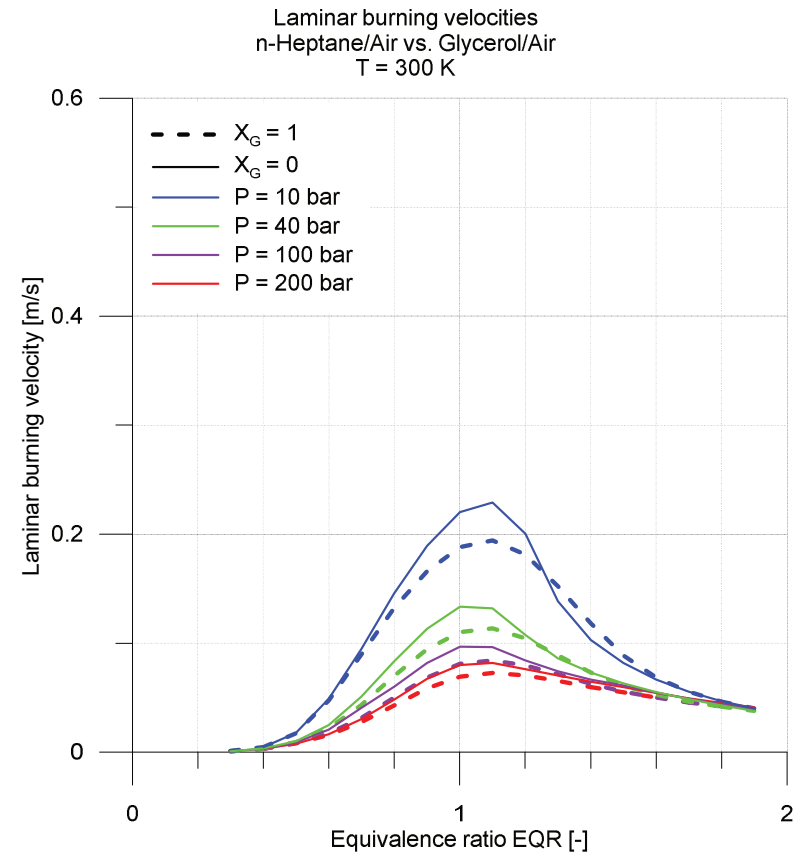

Fig. 13. Laminar burning velocity for $n$-heptane/air $\left(\mathrm{X}_{\mathrm{g}}=0\right.$, solid lines $)$ and glycerol/air $\left(\mathrm{X}_{\mathrm{g}}=1\right.$, dashed lines) mixtures for $300 \mathrm{~K}$ and 4 pressures (10 bar - blue line, 40 bar - green line, 100 bar - violet line, 200 bar - red line)

Fig. 14 and Fig. 15 present a comparison of LBV between iso-octane-air and glycerol-air mixtures for $500 \mathrm{~K}$ and $300 \mathrm{~K}$. For lean conditions LBVs are almost identical, for reach condition LBV of glycerol-air are higher, but as the brief valiadtion showed, in this range Liu mechanisms predicts too small LBV of n-heptane/air $20 \%$. This difference is diminished when pressure increases.

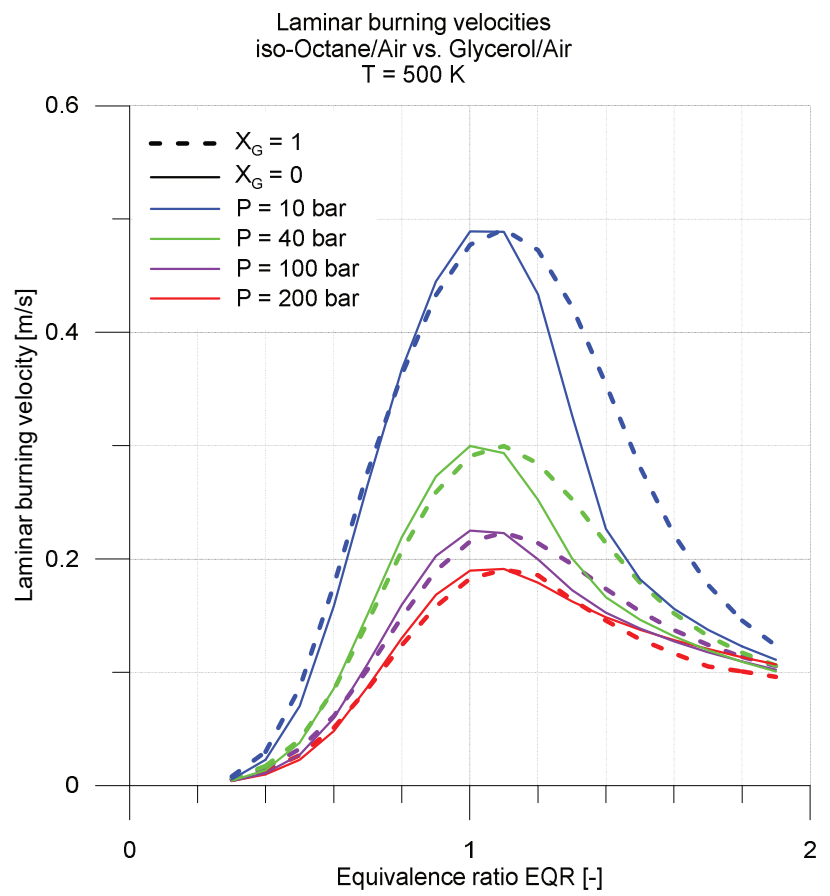

Fig. 14. Laminar burning velocity for iso-octane/air $\left(X_{g}=0\right.$, solid lines $)$ and glycerol/air ( $\mathrm{X}_{\mathrm{g}}=1$, dashed lines) mixtures for $500 \mathrm{~K}$ and 4 pressures (10 bar - blue line, 40 bar - green line, 100 bar - violet line, 200 bar - red line) 


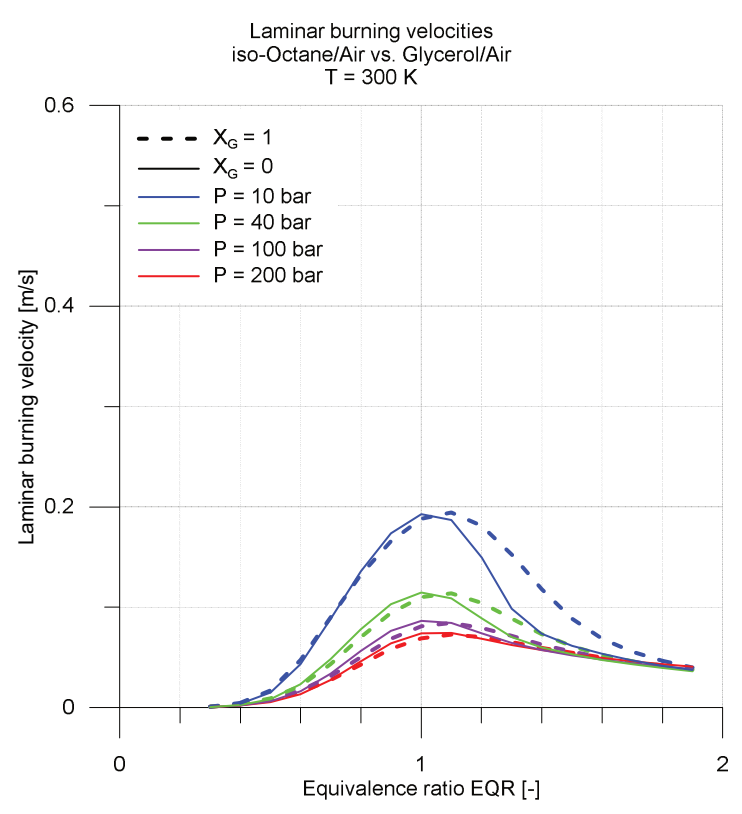

Fig. 15. Laminar burning velocity for iso-octane/air $\left(\mathrm{X}_{\mathrm{g}}=0\right.$, solid lines $)$ and glycerol/air $\left(\mathrm{X}_{\mathrm{g}}=1\right.$, dashed lines) mixtures for $300 \mathrm{~K}$ and 4 pressures (10 bar - blue line, $40 \mathrm{bar}$ - green line, $100 \mathrm{bar}$ - violet line, $200 \mathrm{bar}$ - red line)

\subsection{Kinematic viscosity}

Kinematic viscosity of the fuel directly governs fuel flow, spray and atomization, it impacts the performance of fuel injection system [10]. When kinematic viscosity is high fuel pump consumption is higher and atomization of the fuel poor. It can also cause damage of equipment - i.e. filter damage. If viscosity is too low pump and fuel systems can experience leakage, excessive wear and power loss.

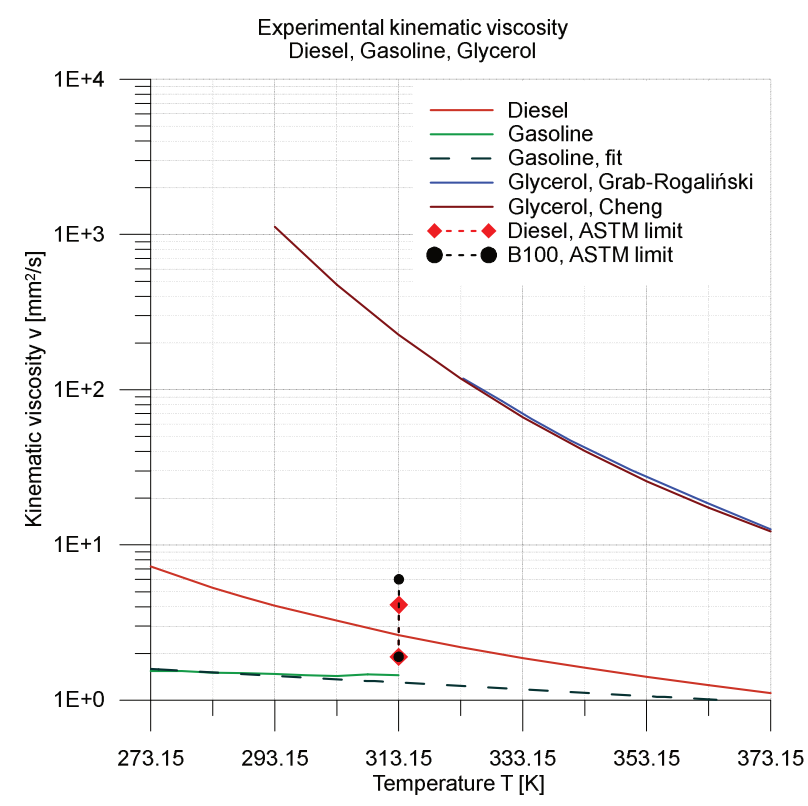

Fig. 16. Experimental kinematic viscosities of diesel oil [23], gasoline [24] and glycerol $[25,26]$ (ASTM limit for $40^{\circ} \mathrm{C}$ are marked for diesel oil and B100 - biodiesel)

Fig. 16 present experimental kinematic viscosities of diesel oil [23], gasoline [24] and glycerol [25, 26]. ASTM limits [10] for diesel oil $\left(1.9-4.1 \mathrm{~mm}^{2} / \mathrm{s}\right.$ for $\left.40^{\circ} \mathrm{C}\right)$ and B100, biodiesel $\left(1.9-6 \mathrm{~mm}^{2} / \mathrm{s}\right.$ for $\left.40^{\circ} \mathrm{C}\right)$ are marked by red rhomb and black circle respectively. Available literature data on gasoline's viscosity does not exceed $40^{\circ} \mathrm{C}$. To enable further analysis the data are extrapolated up to $100^{\circ} \mathrm{C}$. Viscosity is temperature dependent and i.e. obeys exponential model proposed firstly by Reynolds in 1888. In this case the exponential model of viscosity well enough fits the experimental data:

$$
\mathrm{v}_{\text {gasoline }}=6.24826 \cdot \exp (-0.00502 \cdot \mathrm{T}), \mathrm{R}^{2}=0.958
$$

Fitted function of $\mathrm{v}_{\text {gasoline }}$ is presented on Fig. 16.

Glycerol is a very viscous liquid, whose melting point is $18.2^{\circ} \mathrm{C}$ [2]. It's viscosity is over 2 orders $\left(20^{\circ} \mathrm{C}\right)$ to 1 order $\left(100^{\circ} \mathrm{C}\right)$ of magnitude higher than diesel's. In comparison to gasoline it is almost 3 orders to 1 order of magnitude. It is outside limits suggested by ASTM for diesel and biodiesel. In order to make glycerol useful in engine applications it need to be heated up or mixed with a less viscous fuel.

As mentioned above, glycerol does not freely dissolve in hydrocarbons. These mixtures segregate after $\sim 15$ minutes, but it is possible to create a stable mixture with surfactant [8]. Next figures present kinematics viscosity of mixtures of diesel/glycerol and gasoline/glycerol.

In order to assess kinematic viscosities of these dual mixtures a mixing rule of Arrhenius [27] is applied:

$$
\log \mathrm{v}_{\mathrm{blend}}=\mathrm{X}_{\mathrm{v} 1} \cdot \log \mathrm{v}_{1}+\mathrm{X}_{\mathrm{v} 2} \cdot \log \mathrm{v}_{2}
$$

which gave very similar results to validated Kanaveli's mixing rule with additional parameters [27]:

$$
\begin{aligned}
\ln \mathrm{v}_{\mathrm{blend}} & =\mathrm{X}_{\mathrm{v} 1} \cdot \ln \mathrm{v}_{1}+\mathrm{X}_{\mathrm{v} 2} \cdot \ln \mathrm{v}_{2}+\mathrm{X}_{\mathrm{v} 1} \cdot \mathrm{X}_{\mathrm{v} 2} \cdot \mathrm{k} \\
\mathrm{k} & =0.053 \cdot \ln \left(\ln \left(\mathrm{v}_{1} / \mathrm{v}_{2}\right)\right)+0.004
\end{aligned}
$$

Fig. 17 and Fig. 18 present an influence of glycerol doping on diesel's kinematic viscosity. The mixtures complies with ASTM limit for biodiesel for glycerol molar fraction up to $19 \%$ and for diesel up to $10 \%$. Fig. 19 presents kinematic viscosity of gasoline-glycerol blends. Gasoline has

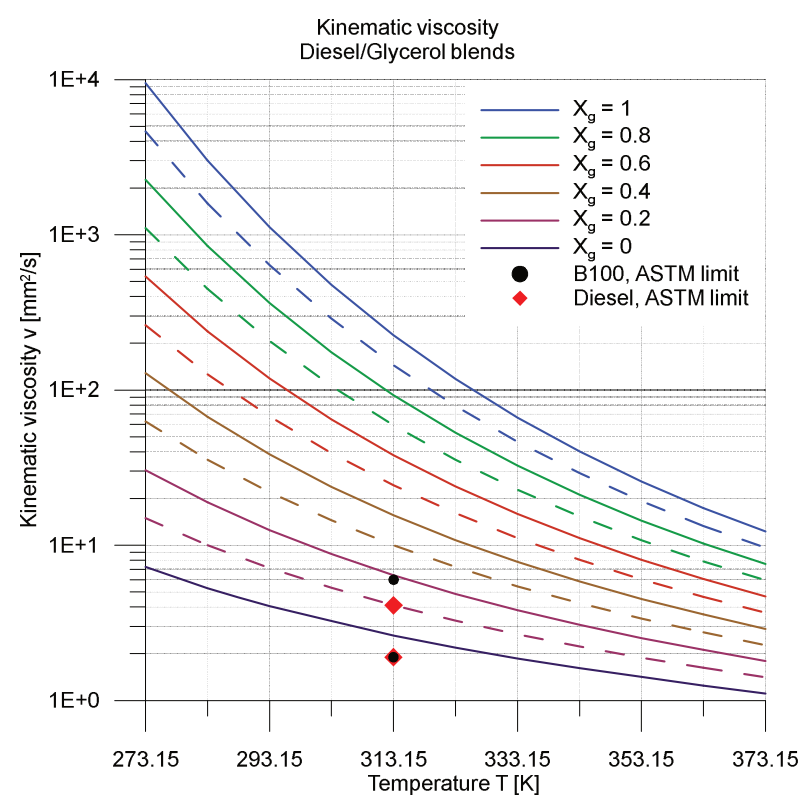

Fig. 17. Kinematic viscosity of diesel - glycerol mixtures vs. temperature. ASTM limits for diesel oil and biodiesel (B100) are marked by red rhomb and black circle respectively 


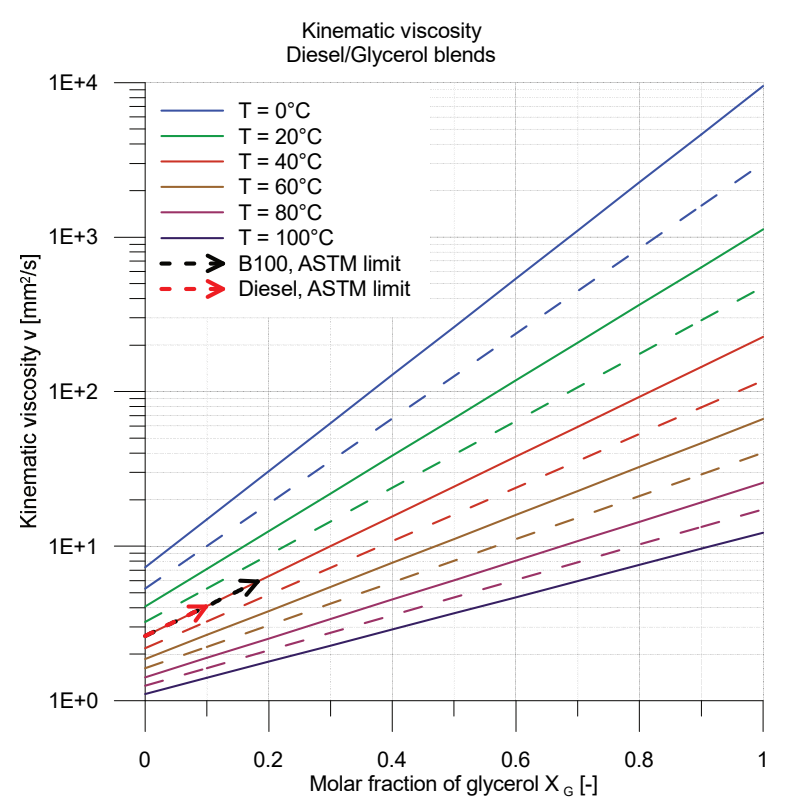

Fig. 18. Kinematic viscosity of diesel - glycerol mixtures vs. molar fraction of glycerol $\mathrm{X}_{\mathrm{g}}$. ASTM limits for diesel oil and biodiesel (B100) are marked by red arrow and black arrow respectively

lower viscosity than diesel oil. Glycerol has stronger influence in increasing viscosity of gasoline blends than of diesel blends.

\subsection{The other properties}

Table 1 summarizes the other important properties diesel, gasoline and glycerol. Glycerol has the highest density. Lower density decreases energy concentration of fuel, increses the risk of leakage. To high density may result in increase of enigne deposition and smoke [10].

Adiabatic flame temperature of glycerol is lower $\sim 200$ $\mathrm{K}$ than diesel's or gasoline's, this is the reason of lower $\mathrm{NO}_{\mathrm{x}}$ of the engines switched to glycerol.

Heat of vaporization of glycerol is 3 times higher than diesel's and gasoline's. Utilization of glycerol as a fuel will result in cooling of the fresh charge (mainly in direct injection engines) during vaporization [28].

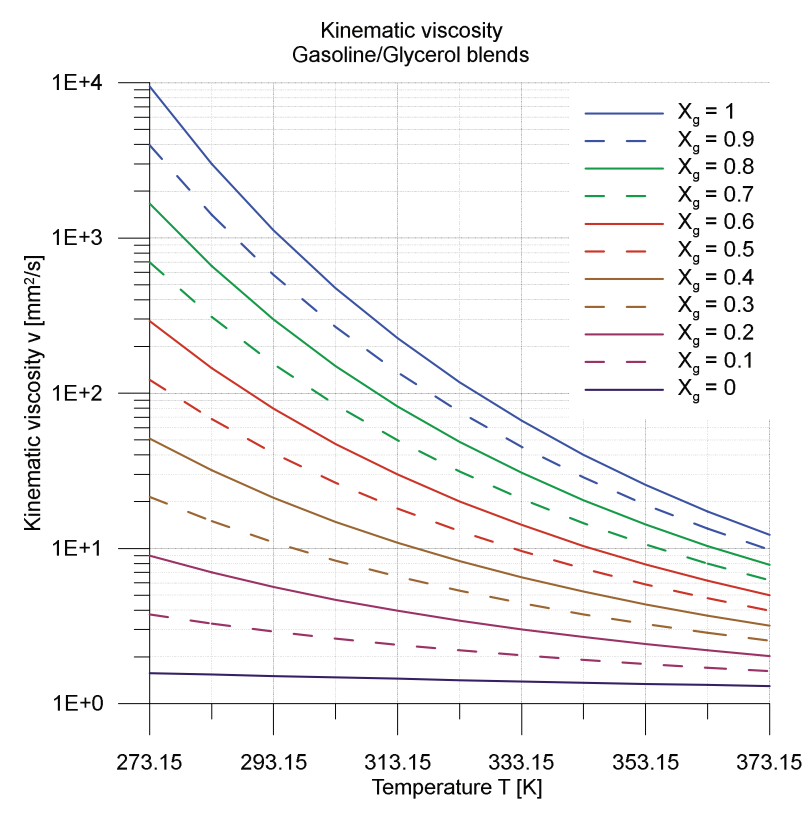

Fig. 19. Kinematic viscosity of gasoline - glycerol mixtures vs. temperature

The flashpoint is the lowest fuel temperature at which the vapor above a fuel sample will momentarily ignite under the prescribed test conditions. Fuel with a higher flash point is considered safer and easier to store. Glycerol has high flash point so fire hazard is low even when exposed to heat or flame, but glycerine is still combustible [2]. ASTM limits of flash point for diesel oil is $130^{\circ} \mathrm{C}$ [10].

Cetane number of glycerol is 5 and is much lower than cetane number of diesel (52). ASTM limit for cetane number of biodiesel is min 47. A compression ignition engine cannot be switched to pure glycerol without any adaptation. Based on comparison of cetane numbers of glycerol and gasoline one can state that glycerol has anti-knocking property.

Table 1. Fuels properties (glycerol [3, 29], diesel [3], gasoline [30])

\begin{tabular}{|l|c|c|c|c|}
\hline Property & Unit & Glycerol & Diesel & Gasoline \\
\hline Molecular Weight & {$[\mathrm{g} / \mathrm{mole}]$} & 92.09 & $150-250$ & $60-150$ \\
\hline Color & - & colorless liquid & amber & yellowish \\
\hline Density & {$\left[\mathrm{g} / \mathrm{cm}^{3}\right]$} & 1.260 & 0.832 & $0.67-0.8$ \\
\hline Pour point & {$[\mathrm{K}]$} & - & 264.67 & - \\
\hline Cloud point & {$[\mathrm{K}]$} & - & 239 & - \\
\hline Melting point & {$[\mathrm{K}]$} & 290 & 264.9 & 252 \\
\hline Boiling point & {$[\mathrm{K}]$} & 563 & $450-463$ & 312 \\
\hline Cetane number & - & 5 & 52 & 12 \\
\hline Higher heating value & {$[\mathrm{MJ} / \mathrm{kg}]$} & 18.6 & 46 & 45.4 \\
\hline Adiabatic flame temperature & {$[\mathrm{K}]$} & 2201 & 2413 & 2411 \\
\hline Heat of vaporization & {$[\mathrm{kJ} / \mathrm{kg}]$} & 670 & $225-280$ & $275-365$ \\
\hline Flash point & {$[\mathrm{K}]$} & 450 & $422-644$ & 227 \\
\hline Autoignition temperature & {$[\mathrm{K}]$} & 666 & 503 & $519-553$ \\
\hline Low flammability limit & {$[\mathrm{vol} \%]$} & 3 & 0.6 & 1.4 \\
\hline High flammability limit & {$[\mathrm{vol} \%]$} & 19 & $5.6-6.5$ & 7.4 \\
\hline
\end{tabular}


The autoignition temperature of a substance is the lowest temperature at which it spontaneously ignites in normal atmosphere without an external source of ignition, such as a flame or spark. Glycerol has the highest autoignition temperature. The flammable limit is the range of a fuel concentration that will burn or explode if an ignition source is introduced.

Cloud point refers to the temperature below which wax in diesel or biowax in biodiesels forms a cloudy appearance. Pour point is the lowest temperature at wich the fuel can still be moved, before it has gelled [31]. For authors best knowledge there are no experimental information on pour points and cloud points of glycerol and gasoline in literature. Taking into account higher freezing (melting) temperature one can assume that both cloud point and pour point are higher than of gasoline and diesel.

\section{Conclusion}

The goal of this paper was to analyze the basic properties of gasoline, diesel and glycerol and their blends, such as ignition delay times and laminar burning velocities. Calculations are performed with use of Cantera tool in Matlab and Python environments. Validation the chemical kinetics mechanisms for reproduction of ignition delay times and laminar burning velocities of both n-heptane/air and iso-octane/air was performed. Interest in glycerol as a fuel is relatively new, therefore experimental data on ignition delay times and laminar burning velocities are not yet present in literature.
Analyses of influence of glycerol on ignition delay times of n-heptane/air and iso-octane/air mixtures covered wide range of conditions: temperatures from 600 to $1600 \mathrm{~K}$, pressure 10-200 bar, equivalence ratio 0.3 to 14 , molar fraction of glycerol in fuel 0-1 (from pure n-heptane or isooctane to pure glycerol) in air. Simulations of LBV in air cover temperatures: $300 \mathrm{~K}$ and $500 \mathrm{~K}$, pressures: 10 , 40, 100,200 bar and equivalence ratio from 0.3 to 1.9 .

Glycerol has anti-knock properties for ignition temperatures lower than $900 \mathrm{~K}$, based on calculated IDT of isooctane/glycerol/air mixtures and cetane number of gasoline and glycerol. However to notice this influence molar fraction of glycerol in a fuel needs to be min. $\sim 50 \%$. LBV of glycerol and iso-octane is comparable.

Glycerol has longer IDT than n-heptane for temperatures lower than $1000 \mathrm{~K}$. The highest difference is present for $n$-heptane/air negative temperature coefficient region. For local minimum $(\mathrm{T}=830 \mathrm{~K}$, n-heptane: $\mathrm{IDT}=400 \mu \mathrm{s})$ it may reach even 2 orders of magnitude (glycerol: IDT $=20$ $\mathrm{ms}$ ). On the other hand, in order to change IDT of nheptane using glycerol, glycerol molar fraction need to make up at least $50 \%$. Small amounts of glycerol should not worsen ignitability. To fulfill ASTM limit for kinematic viscosity of diesel and biodiesel the amount of glycerol should not exceed $10 \%$ and $19 \%$ respectively. However, in the ASTM limit there is also requirement that maximal allowed fraction of glycerin in biodiesel does not exceed $0.24 \%$ mass and it is important in terms of injector depositions and filter plugging.

\section{Nomenclature}

\begin{tabular}{|c|c|c|c|}
\hline IDT & ignition delay time & EQR & equivalence ratio \\
\hline LBV & laminar burning velocity & $\mathrm{V}$ & kinematic viscosity \\
\hline LFO & light fuel oil & $\mathrm{k}$ & parameter in Kanaveli's mixing rule \\
\hline FAME & fatty acid methyl esters & $\mathrm{g}$ & glycerol \\
\hline PM & particulate matter & $\mathrm{B} 100$ & $100 \%$ of biodiesel \\
\hline NOx & nitirc oxides & E95 & $95 \%$ of ethanol and $5 \%$ of gasoline \\
\hline NTC & negative temperature coefficient & ASTM & American Society for Testing and Materials \\
\hline $\mathrm{T}$ & temperature & ERC & Engine Research Centre \\
\hline $\mathrm{P}$ & pressure & POLIMI & Polytechnic University of Milan \\
\hline $\mathrm{X}$ & molar fraction & & \\
\hline
\end{tabular}

\section{Bibliography}

[1] European Biofuels Technology Platform, Fatty Acid Methyl Esters (FAME). Biofuel Fact Sheet. 2011, 1, 1-2.

[2] MINER, C., DALTON, N.N. Glycerine: an overview. Chem Soc Monogr. 1953, 117(212), 1-27.

[3] SETYAWAN, H.Y., ZHU, M., ZHANG, Z., ZHANG, D. Ignition and combustion characteristics of single droplets of a crude glycerol in comparison with pure glycerol, petroleum diesel, biodiesel and ethanol. Energy. 2016, 113, 153-159.

[4] Rychlik A., Application of glycerine for powering piston diesel engines of large power. Combustion Engines. 2015, 162(3), 644-648, 2015.

[5] MCNEIL, J., DAY, P., SIROVSKI, F. Glycerine from biodiesel: the perfect diesel fuel. Process Saf. Environ. Prot. 2012, 90(3), 180-188.

[6] STELMASIAK, Z., PIETRAS, D. Utilization of waste glycerin to fuelling of spark ignition engines. IOP Conf. Ser. Mater. Sci. Eng. 2016, 148, 12087.
[7] GRAB-ROGALINSKI, K.. SZWAJA, S. The possibility of use a waste product of biofuels production-glycerol as a fuel to the compression ignition engine. J. KONES. 2016, 23(3), 157-164.

[8] EATON, S.J. et al. Formulation and combustion of glyceroldiesel fuel emulsions. Energy and Fuels. 2014, 28(6), 39403947.

[9] ARBAB, M.I., MASJUKI, H.H., VARMAN, M. et al. Fuel properties, engine performance and emission characteristic of common biodiesels as a renewable and sustainable source of fuel. Renew. Sustain. Energy Rev. 2013, 22, 133-147.

[10] KESLING, H.S., KARAS, L.J., LIOTTA, F.J. Diesel fuel. 1994.

[11] RANZI, E. et al. Chemical kinetics of biomass pyrolysis. Energy \& Fuels. 2008, 22(6), 4292-4300.

[12] DUPONT, C. et al. Biomass pyrolysis: kinetic modelling and experimental validation under high temperature and flash heating rate conditions. J. Anal. Appl. Pyrolysis. 2009, 85(1-2), 260-267. 
[13] CALONACI, M., GRANA, R., BARKER HEMINGS, E. et al. Comprehensive kinetic modeling study of bio-oil formation from fast pyrolysis of biomass. Energy \& Fuels. 2010, 24(10), 5727-5734.

[14] Hemings, E.B., CAVAllotTi, C., CUOCI, A. et al. A detailed kinetic study of pyrolysis and oxidation of glycerol (propane-1,2,3-triol). Combust. Sci. Technol. 2012, 184(78), 1164-1178.

[15] CORBETTA, M. et al. Pyrolysis of centimeter-scale woody biomass particles: kinetic modeling and experimental validation. Energy \& Fuels. 2014, 28(6), 3884-3898.

[16] DEE, V., SHAW, B.D. Combustion of propanol-glycerol mixture droplets in reduced gravity. Int. J. Heat Mass Transf. 2004, 47(22), 4857-4867.

[17] RANZI, E. et al. Hierarchical and comparative kinetic modeling of laminar flame speeds of hydrocarbon and oxygenated fuels. Prog. Energy Combust. Sci. 2012, 38(4), 468-501.

[18] HARTMANN, M., GUSHTEROVA, I., FIKRI, M. et al. Auto-ignition of toluene-doped n-heptane and iso-octane/air mixtures: high-pressure shock-tube experiments and kinetics modeling. Combust. Flame. 2011, 158(1), 172-178.

[19] ZHANG, K. et al. An updated experimental and kinetic modeling study of n-heptane oxidation. Combust. Flame. 2016, 172, 116-135.

[20] GOODWIN, D.G., MOFFAT, H., SPETH, R.L. Cantera: an object-oriented software toolkit for chemical kinetics, thermodynamics, and transport processes. 2017.

[21] JERZEMBECK, S., PETERS, N., PEPIOT-DESJARDINS, P., PITSCH, H. Laminar burning velocities at high pressure for primary reference fuels and gasoline: experimental and numerical investigation. Combust. Flame. 2009, 156(2), 292-301.

Agnieszka Jach, MSc. - Faculty of Power and Aeronautical Engineering at Warsaw University of Technology.

e-mail: AJach@itc.pw.edu.pl

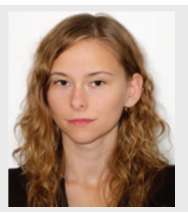

Prof. Andrzej Teodorczyk, DSc., DEng. - Faculty of Power and Aeronautical Engineering at Warsaw University of Technology.

e-mail:ATeod@itc.pw.edu.pl

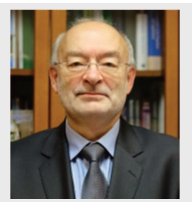

[22] LIU, Y., JIA, M., XIE, M., PANG, B. Improvement on a skeletal chemical kinetic model of iso-octane for internal combustion engine by using a practical methodology. Fuel. 2013, 103, 884-891.

[23] BARABÁS, I., TODORUŢ, I.A. Predicting the temperature dependent viscosity of biodiesel-diesel-bioethanol blends. Energy and Fuels. 2011, 25(12), 5767-5774.

[24] KUMAR, P., KISHAN, P.A., DHAR, A. Numerical investigation of pressure and temperature influence on flame speed in $\mathrm{CH} 4-\mathrm{H} 2$ premixed combustion. Int. J. Hydrogen Energy. 2016, 41(22), 9644-9652.

[25] CHENG N.-S. Formula for the viscosity of a glycerol-water mixture. Ind. Eng. Chem. Res. 2008, 47(9), 3285-3288.

[26] GRAB-ROGALINSKI, K., SZWAJA, S. The combustion properties analysis of various liquid fuels based on crude oil and renewables. IOP Conf. Ser. Mater. Sci. Eng. 2016, 148, 12066.

[27] KANAVELI, I.-P., ATZEMI, M., LOIS, E. Predicting the viscosity of diesel/biodiesel blends. Fuel. 2017, 199, 248263.

[28] STEIN, R.A. et al. Effect of heat of vaporization, chemical octane, and sensitivity on knock limit for ethanol - gasoline blends. SAE Int. J. Fuels Lubr. 2012, 5(2), 2012-01-1277.

[29] QUISPE, C.A.G., CORONADO, C.J.R., CARVALHO, J.A. Glycerol: production, consumption, prices, characterization and new trends in combustion. Renew. Sustain. Energy Rev. 2013, 27, 475-493.

[30] P. Information 3. Chemical and Physical Information 3.1, 1990.

[31] ALPTEKIN, E., CANAKCI, M. Characterization of the key fuel properties of methyl ester-diesel fuel blends. Fuel. 2009, 88(1), 75-80.

Ilona Cieślak, MSc. - Faculty of Power and Aeronautical Engineering at Warsaw University of Technology.

e-mail:ICieslak@itc.pw.edu.pl

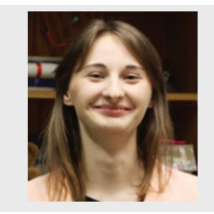

